\title{
Characteristics and Outcomes of Frail Patients with COVID-19 Admitted to ICU: An Individual Patient Data Meta-Analysis
}

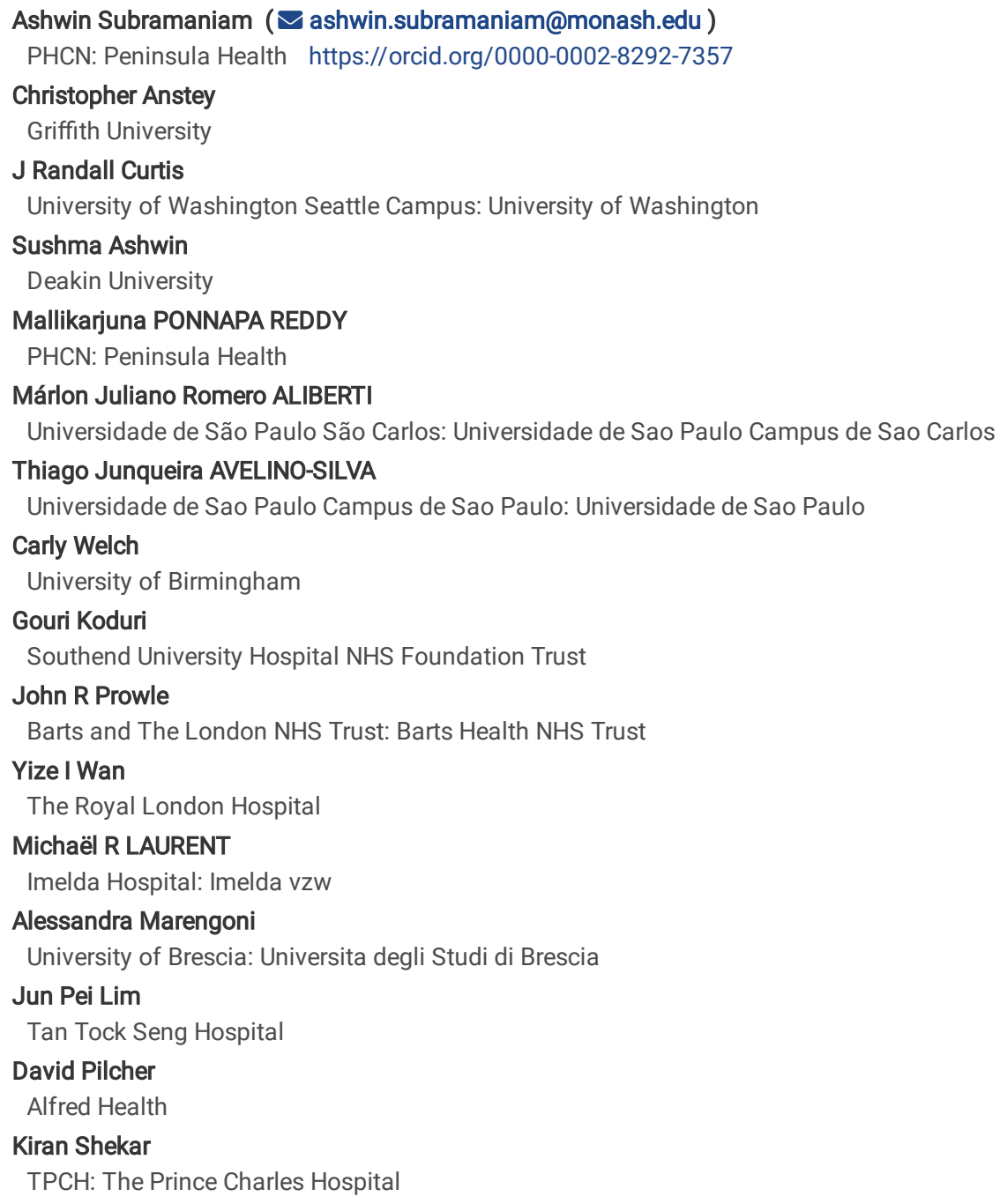




\section{Abstract}

Purpose: Frailty is often used in clinical decision-making for patients with COVID-19, yet studies have found variable influence of frailty on outcomes in those admitted to the intensive care unit (ICU). In this individual patient data meta-analysis, we evaluated the characteristics, and outcomes of frail patients admitted to ICU with COVID-19.

Methods: We contacted the corresponding authors of sixteen eligible studies published between December $1^{\text {st }} 2019$ and February $28^{\text {th }} 2021$ reporting the clinical frailty scale (CFS) in patients with confirmed COVID-19 admitted to ICU. Individual patient data was obtained from 7 studies. We classified patients as non-frail (CFS=1-4) or frail (CFS=5-8). The primary outcome was hospital mortality. We also compared the use of mechanical ventilation (MV) and the proportion of ICU bed-days between frailty categories.

Results: Of the 2001 patients admitted to ICU, 388 (19.4\%) were frail. Increasing age and sequential organ failure assessment (SOFA) score, CFS $\geq 4$, use of $\mathrm{MV}$, vasopressors, renal replacement therapy and hyperlactatemia were risk factors for death in a multivariable analysis. Hospital mortality was higher in frail patients $(65.2 \%$ vs. $41.8 \%$; $<<0.001)$, with adjusted mortality increasing with a rising CFS score beyond 3 . Younger and non-frail patients were more likely to receive MV. Frail patients spent less time on MV (median days [IQR] 9 [5-16] vs. 11 [6-18]; p=0.012) and accounted for only $12.3 \%$ of total ICU bed-days.

Conclusion: Frail patients with COVID-19 were commonly admitted to ICU and had greater hospital mortality but spent relatively fewer days in ICU when compared with non-frail patients. Frail patients receiving MV were at greater risk of death than non-frail patients.

Systematic review registration: Registration protocol in PROSPERO (CRD42020224255).

\section{Take Home Message}

One in five ICU patients admitted to the ICU with COVID-19 were frail and were more likely to die in hospital. Patients with a clinical frailty score greater than 3 were at a higher risk of death. Half the patients received mechanical ventilation and mechanical ventilation was preferentially used in the younger and nonfrail patients. Frail patients spent shorter duration on mechanical ventilation and only accounted for $12.3 \%$ of total ICU bed-days.

\section{Background}

Older patients (aged $\geq 65$ years [1]) are major users of acute health care [2], making up an increasing proportion of patients admitted to intensive care units (ICUs) $[3,4]$. Although older patients have an increased risk of death in the ICUs, estimating risks in acutely ill older people is challenging due to the concomitance of chronic diseases and age-related conditions [5]. Among the age-related conditions, frailty is an important element of risk. This syndrome reflects a loss of physical, physiological, and cognitive reserves, which makes older people more vulnerable to adverse outcomes in the context of acute stressors [6]. For example, among patients aged 80 years and older, who represent over $40 \%$ of ICU bed-days [7], frailty has been associated with more than double the risk of death and functional dependence [8-10]. It is noteworthy that patients with frailty are particularly vulnerable to infections as they have increased risk of alterations in innate and adaptive immunity and a high burden of chronic diseases and age-related conditions (e.g., cognitive impairment, functional disability, and polypharmacy) [11].

Coronavirus disease 2019 (COVID-19) causes severe respiratory illness in about $13 \%$ of cases and can rapidly transform into a life-threatening illness in about $4 \%$ of cases, particularly those with comorbidities. The life-threatening form of the disease is characterised by severe acute respiratory distress syndrome, cytokine release syndrome, metabolic acidosis, and venous thromboembolism, and/or disseminated intravascular coagulopathy [12]. The surge in critically ill patients with respiratory failure has overwhelmed ICU capacity in many healthcare systems across the world [13, 14]. Studies published during the early phase of the pandemic have shown poor outcomes in mechanically ventilated patients with COVID-19 [15], although some studies suggest survival has improved over time [16,17]. Given that healthcare resources worldwide were overstretched by the unprecedented COVID-19 pandemic, there has been interest in reliable assessment tools to inform patient prioritisation for scarce intensive care resources.

Frailty tools, such as the clinical frailty scale (CFS), have found clinical utility as an adjunct to age-based criteria for critical care triage decisions (The National Institute for Health and Care Excellence, NICE triage guidelines) [18]. However, the guideline has been criticised as it was extrapolated from pre-pandemic data [19]. Many studies have recently been published on the impact of frailty in patients with COVID-19 with some reporting on patients in the ICU. Due to these limitations in existing information, variations in study design, limitations of published data, and the heterogeneity in the measures of frailty, conventional meta-analyses based on these studies will have limited accuracy. We conducted an individual patient data meta-analysis to evaluate the characteristics, and outcomes across the range of frailty in patients with COVID-19 admitted to ICU. Our goal is to provide evidence as to whether the CFS might be used as part of assessment to capture the risk of death beyond chronological age among patients with COVID-19 admitted to the ICU.

\section{Methodology}

The study was registered with PROSPERO (CRD42020224255) and conducted in adherence with the Preferred Reporting Items for Systematic Reviews and Meta-analyses (PRISMA) Statement [20].

Search strategy, information sources, and study selection 
Two authors (AS and SA) independently searched the publicly available COVID-19 living systematic review [21]. It is updated daily to provide a dynamic database of research papers related to COVID-19 that are indexed by PubMed, EMBASE, MedRxiv, and BioRxiv. Studies were extracted between December 1st 2019 and February 28th 2021, using the search terms "frail", and "frailty" within the title and the abstract columns of the systematic review list. Due to the rapidly evolving pandemic, pre-print studies that were yet to be peer-reviewed were included to capture as much data as possible. These terms were combined with the Boolean operator "OR".

\section{Eligibility Criteria}

The corresponding authors of eligible studies [22-38] (Supplementary Table 1) were invited to participate and share their original individual patient data. We included studies that reported on adults aged $\geq 18$ years with laboratory-confirmed symptomatic COVID-19 patients, a documented CFS score and admitted to ICU. Only the patients with hospital outcome were included in the final analysis.

\section{Data extraction}

Data collection included patient demographics (age, sex, comorbidities, ethnicity, ICU admission source, smoking status), CFS score, ICU organ supports, such as the need for mechanical ventilation (MV), non-invasive ventilation, vasopressors, and/or renal replacement therapy); medical treatment limitation order, ICU and hospital mortality, and ICU and hospital length of stay (LOS).

\section{Explanatory variable - frailty}

In the Canadian Study of Health and Aging, CFS based on a 9-point judgement-based categorical scale was used for frailty measurement [39]. This scale has demonstrated validity and reliability in frailty assessment in ICU patients and other populations [8, 39]. This scale includes CFS = 1 (very fit), 2 (well), 3 (managing well), 4 (vulnerable), 5 (mildly frail), 6 (moderately frail), 7 (severely frail), 8 (very severely frail), and 9 (terminally ill) [39]. The modified eightcategory CFS is the most utilised frailty assessment in the critically ill [40]. Frailty scores were also dichotomised as non-frail $(C F S=1-4)$ or frail $(C F S=5-8)$ according to accepted definitions [8], with the frail cohort further considered in terms of mild/moderate frailty (CFS 5-6) and severe/very severe frailty (CFS 7-8).

\section{Ethical Issues}

The individual patient data meta-analysis was exempt from ethics approval because we obtained de-identified data from previously published and ethically approved individual studies.

\section{Other covariates}

Exposure variables such as age, sex, chronic respiratory disease, chronic kidney disease, ischemic heart disease, admission source, SOFA and APACHE 2 scores were investigated as risk factors for hospital mortality in patients with COVID-19.

Main outcome(s): This was a one-stage individual patient data meta-analysis to assess continuous covariates (CFS and age). The primary aim was to evaluate whether frailty scores predicted outcomes for patients with COVID-19 admitted to ICU, including ICU mortality, hospital mortality, and discharge destination after adjusting for age and gender. The primary outcome was hospital mortality. We examined the following secondary outcomes: organ support within the ICU (mechanical and non-invasive ventilation, renal replacement therapy, vasoactive infusion, and extracorporeal membrane oxygenation), length of ICU and hospital stay, ICU bed-days, and discharge destination.

\section{Missing data}

There was minimal missing data for the primary outcome (0.2\%). However, there were missing data with illness severity scores (42.9\%), comorbidities (11.4\%), presenting symptoms (8.2\%), biochemistry within 24 hours of ICU admission (10.5\%), use of non-invasive ventilation (37.8\%), use of invasive mechanical ventilation (IMV, 33.2\%), hospital length of stay (0.7\%) and discharge destination (31.3\%). We did not perform any imputation.

\section{Statistical Analysis}

In this retrospective study, data were initially checked for completeness and validity with queries directed back to the contributing institutions. Normality was assessed in continuous data by employing both normal quantile (probit) plots and the Shapiro-Wilk test. Normally distributed data were reported using the mean (standard deviation [SD]). Non-normal, categorical, and dichotomous data were reported using either the median (interquartile range [IQR]) or number (frequency [\%]) respectively. The final dataset was gathered from seven discrete institutions and all analyses were clustered by the institution. An initial analysis was conducted between survivors and non-survivors to identify the independent predictors of mortality in critically ill patients with COVID-19. When specifically analysing from a clinical frailty point of view, the binary CFS categories non-frail/frail, data were compared using either a standard t-test for normally distributed data, the Wilcoxon rank-sum test for categorical data or the Fisher's exact test for dichotomous data. Comparisons were conducted on demographic, co-morbidity, symptomatology, illness severity score, available within the first 24 hours. ICU and hospital mortality were examined using a logistic model in the primary analysis. Our primary analysis included the CFS scale (1-8) with subsequent adjustment for age and sex. Secondary multivariable logistic models were constructed to examine the effects of age, CFS, obesity measured as body mass index less or greater than $30 \mathrm{~kg} . \mathrm{m}^{-2}$, presence or absence of co-morbidities including active cancer, dementia, and the neutrophil-lymphocyte ratio as a marker of chronic inflammation on ICU mortality with the predictors selected from the results of the univariate analysis described above. Two-way interactions were also tested between the CFS and the significant predictors. Sequential deletion of non-significant predictors with potential misspecification tested using the linktest was conducted at each step of model development. Post-estimation checks for model specification and presence of collinearity were conducted using the link test and variance inflation 
factor respectively. Results were reported as the odds ratio of death with its $95 \%$ confidence interval and p-value. A competing risk analysis was performed next to examine the marginal probability of death using both the presence of ventilation and CFS. The method of Fine and Gray was used to generate the cumulative incidence function [41]. The significant predictors from the logistic model were used and results expressed as sub-hazard ratios and their $95 \%$ confidence intervals. Youden's Y statistic was calculated for each CFS score thus yielding individual sensitivity and specificity results. All analyses were conducted using STATA ${ }^{\mathrm{TM}}$ (version 16.0) with the level of significance set at $\mathrm{a}<0.05$.

\section{Results}

Of the 616 studies identified, sixteen studies [22-36] (Supplementary Table 1) met all eligibility criteria. All sixteen corresponding authors were invited to participate and share their original individual patient data. We included seven studies $[22,26,29,31,32,36,37]$ that provided individual patient data on 9332 hospitalisations (Supplementary Fig. 1), of these, 3690 (39.5\%) patients were deemed frail. There were a total of 2804 patients from the excluded nine studies, of which $476(17 \%)$ were admitted to ICU. It was unclear as to what proportion of these patients were frail (Supplementary Table 1). Off the 2003 patients with CFS scores, 2 patients with CFS scores of 9 were removed. A total of 2001 patients $(21.4 \% ; 2001 / 9332)$ admitted to the ICU were included in the final analysis.

\section{Survivor vs. non-survivor analysis}

The initial analysis identified that $54.1 \%$ (1083/2001) patients admitted to the ICU died (Table 1). The independent predictors that increase the probability of death in these patients with COVID-19 were increasing age, CFS $\geq 4$, increasing SOFA score, use of IMV, dialysis and vasopressors, and rising or high lactate; a history of hypertension was associated with a lower likelihood of death (Table 2, Supplementary Tables 2; Supplementary Fig. 2).

\section{Analysis based on frailty status}

One of the major predictors of mortality in patients with COVID-19 was their frailty status. Of the 2001 included patients admitted to the ICU, $80.6 \%$ (1613/2001) were non-frail and 19.4\% (388/2001) were frail (Supplementary Table 3). Frailty increased with advancing age (Supplementary Fig. 3). The baseline characteristics, presenting symptoms, biochemistry and acid-base between frail and non-frail patients are presented in Table 3. Non-frail patients were more likely to have presenting symptoms such as fever, and myalgia/lethargy, while frail patients were more likely to present with delirium. The time from symptoms to hospitalisation was shorter for frail patients when compared to non-frail patients (median [IQR] days $7[4,10]$ vs. $8[5,11] ; p=0.001)$. Frail patients were more likely to have an accompanying acute kidney injury. They were also more lymphopaenic with a higher neutrophil-to-lymphocyte ratio than non-frail patients. A lower proportion of male patients were frail $(47 \% \mathrm{vs.} 54 \% ; p<0.001)$. Although home residence was similar, there were a higher proportion of frail than non-frail patients residing in 24-hour long-term facility ( $8.8 \%$ vs. $2.0 \%$; $p=0.002$ ) before the index hospitalisation. The patients classified as frail were older and had higher illness severity scores (Simplified Acute Physiology Score 2 [SAPS-2], Supplementary Table 4). The frail patients also had higher chronic comorbidities, particularly hypertension, cardiovascular disease, diabetes mellitus, active cancer, and dementia, but were less likely to be obese (BMI $\geq$ $30 \mathrm{~kg} \cdot \mathrm{m}^{-2}$ ) (Supplementary Table 5).

\section{Primary Analyses of Primary Outcome}

Frail patients were more likely to die in ICU (unadjusted mortality $26.8 \%$ vs. $17.9 \% ; p=0.044$ ) and in hospital (unadjusted mortality $65.2 \%$ vs. $41.8 \%$; $p<0.001$ ). Frailty status, after adjusting for age and sex, was independently associated with hospital mortality but not ICU mortality (Table 4, Fig. 1, panels a and b). In secondary analyses, the relationship between frailty and hospital mortality remained significant independent of age, BMI, and neutrophil-lymphocyte ratio (Supplementary Table 6).

\section{Secondary Outcomes}

The raw outcomes are presented in Supplementary Table 5.

\section{Mechanical ventilation}

1014 of the 2001 patients (50.7\%) received MV, most of them had a CFS score between 2 and 4 (Fig. 1, panel c). Of these 1014 patients who received MV, there was no difference between frail and non-frail patients $(51.2 \%$ [199/388] vs. 50.5\% [815/1613]; $p=0.79)$. However, frail patients spent shorter median [IQR] duration on MV ( 9 days [5-16] vs. 11 days [6-18]; $p=0.012$ ). The unadjusted mortality rates were higher in patients requiring MV than those who did not (Supplementary Tables 7 and 8, Supplementary Figs. 4). All patients with CFS 8 who were mechanically ventilated died. Figure 2 describes the cumulative risk of death overtime amongst patients who received $\mathrm{MV}$, which demonstrated that the cumulative risk of death decreases with more days on mechanical ventilation. Multivariable linear regression in ICU survivors indicated that the adjusted geometric mean duration of MV reduced significantly with increasing CFS score (from 9.5 days [8.3-10.7] for CFS 1 to 3.6 [2.3-5.0] for CFS 7 and 8 combined) (Table 4).

\section{ICU and Hospital Length of stay}

Frail patients admitted to ICU were more likely to have shorter median [IQR] LOS in ICU (8 days [4, 16] vs. 11 days [5, 20]; $p<0.001)$. Of the total $24.3 \times 1000$ ICU bed-days, frail patients only contribute $12.3 \%$ of the ICU bed-days (Fig. 3). Similar findings were observed when only survivors were analysed. Patients with CFS 7 and 8 spent the shortest time in ICU $(0.6 \times 1000$ ICU bed-days, 2.5\%). However, the ICU bed-days occupied by frail patients who died was almost double that of survivors for CFS 5-7. Frail patients also had shorter median [IQR] hospital length of stay $(13$ days $[8,23]$ vs. 16 days [10, 28]; $p<0.001)$ when compared to non-frail patients (Supplementary Table 7). Heat map comparing age- and CFS-stratified data based on ICU survivors and ICU non-survivors demonstrated that most patients admitted to ICU were younger than 80 years of age and CFS $\leq 6$ (Supplementary Fig. 5).

\section{Other organ support}


Frail patients were less likely to receive non-invasive ventilation ( $27 \%$ vs. $35 \% ; p=0.011)$ or renal replacement therapy $(25 \%$ vs. $32 \%$; $p=0.026)$ when compared to non-frail patients. There was no difference in vasopressor infusion use between frail and non-frail patients (Supplementary Table 8).

\section{Discharge Destination}

Frail patients were less likely to be discharged home (unadjusted $23 \%$ vs. $45 \%$; $p<0.001$ ), and rehabilitation (unadjusted $23 \%$ vs. $35 \%$; $p<0.001$ ). However, the unadjusted new discharges to 24 -hour long-term facility discharge $(1.5 \%$ vs. $2.3 \%$; $=0.17)$ were similar between frail and non-frail patients (Supplementary Tables 9 and 10).

\section{Discussion}

This multinational individual patient data meta-analysis included 2001 patients with COVID-19 admitted to an ICU from seven studies identified the following five key findings. First, increasing age and SOFA score, CFS $\geq 4$, use of MV, vasopressors, renal replacement therapy and hyperlactatemia were independent predictors of mortality. Second, A fifth of the patients admitted to ICU were frail, with almost two-thirds of these frail patients dying in hospital. The odds of hospital mortality increased from a CFS score of 3. Multivariable analysis demonstrated that older age and increasing frailty were independently associated with hospital mortality. Third, the impact of frailty on the use of MV differed with age, with younger and non-frail patients being more likely to receive MV. Fourth, the frail ICU survivors received shorter duration of MV and had shorter ICU length of stay. Fifth, the frail patients' ICU bed-days occupancy was only $16 \%$ and spent a shorter time in ICU. This final finding may relate to decisions to limit invasive and burdensome treatments.

The hospital mortality of patients with COVID-19 admitted to ICU has ranged widely depending on the geographical location and the different levels of strain on the critical care system [23, 27, 29, 30, 36, 42-50]. A large cohort study of patients with COVID-19 treated in ICU during periods of peak COVID-19 found a two-fold increase in mortality compared to those treated during periods of low demand [42]. Furthermore, several studies have demonstrated an association of higher mortality with increased hospital or regional COVID-19 caseloads, regardless of whether the patients were frail or not [51]. These findings suggest the importance of caution in interpreting results from different time periods.

A single-centre retrospective study from Italy of 105 patients observed that the frailty index was an independent predictor of both higher in-hospital mortality and lower proportions with ICU admission [52]. A recent large prospective multinational study (COVIP) identified that frailty was independently associated with lower survival [53]. Similarly, our individual patient data meta-analysis also observed that frailty was independently associated with hospital mortality amongst patients with COVID-19 admitted to ICU. A nationwide Turkish study of patients 65 years and over, using the hospital frailty risk score, observed that frailty was independently associated with hospital mortality, ICU admission, and use of MV [44]. These studies may suggest that the high risk of mortality in older patients along with ICU resource constraints may raise the question of triaging ICU admissions. Even in times of non-constrained resources, shared decision-making may be informed by risk of mortality assessments, to allow patients and their caregivers to make informed choices about their care. A recent systematic review and meta-analysis recommended that frailty screening may be helpful to stratify high-risk groups [54].

Our study observed MV was used more often among younger and non-frail patients. This was consistent with a recent study in non-COVID patients that investigated the impact of frailty on duration of ventilation where they observed frail young patients had longer duration of ventilation, but not old frail patients [55]. In a recent large systematic review, the reported mortality in mechanically ventilated patients was $45 \%$ and was significantly higher with increasing age and higher among those receiving mechanical ventilation [15]. In our meta-analysis, frail patients, both survivors and non-survivors, spent a shorter time on MV. This finding implies that the patients with frailty may have died sooner or may have had treatment limitations.

We identified that non-frail patients accounted for $85 \%$ of the ICU bed-days. This is contrary to the findings of a recent study of older non-COVID-19 ICU patients with pneumonia which found a significantly higher ICU bed occupancy by frail patients [56]. Furthermore, the findings that frail ICU survivors received shorter duration of MV and had shorter ICU LOS are noteworthy and somewhat counterintuitive. This finding may be influenced by differing patterns of care for frail older adults between countries, resource constraints related to patient triage and possibly earlier decisions to limit life-sustaining treatments in these patients.

Even before the COVID-19 pandemic began, frailty was recognised as a predictive factor for adverse outcomes, such as mortality [57], hospitalisations [58], and readmission [59]. Consequently, frailty was proposed as an important aspect to patient assessment early in the pandemic. Despite the stringent guidelines, the patients with COVID-19 remained eligible for ICU admission under the NICE guidelines, particularly following a ward deterioration. However, triaging patients just based on the frailty status is not justified by the current data $[60,61]$. Indeed, an odds ratio of $\sim 2$ by itself is not useful clinically. A patient-centred approach to triage that incorporates frailty screening could be developed to rapidly assess patients for the severity of the presenting acute illness and the likelihood of medical interventions being successful [62]. An option of triage committee involvement to provide an ethical framework to guide clinicians to equitable rationing under crisis standards of care has been proposed [63, 64].

Our study has several notable strengths. First, we had high-quality data from the seven included studies from diverse countries, both developing and developed, at their peak of the pandemic. Second, the CFS, which is the most used frailty assessment tool for critically ill patients, was used in all the included studies. Finally, we incorporated several secondary analyses, including the competing risk analyses, to assess the impact of frailty on diverse ICU outcomes.

Our study also has several notable limitations. First, the datasets from the seven included had missing data for a proportion of covariates, such as APACHE scores. Second, it is important to acknowledge that the results may have been predominantly influenced by two main studies, one of which was a single centre study. Third, the differences in the healthcare systems across the different studies included in this individual patient data meta-analysis may introduce variability that is difficult to address with clustering by institution. Fourth, although there is evidence that COVID-19 has a disproportionate impact on disease severity and mortality in minority racial and ethnic groups, we did not have adequate data on the patient race or ethnicity [22]. Fifth, although our seven 
studies were from different countries, our sample may not be globally representative. Sixth, although patients with frailty tend to have treatment limitations (do not resuscitate, do not intubate, etc.) [65], which may guide their management, we did not have data on treatment limitations or pre-ICU triage decisions which undoubtedly influenced our results. Finally, although imprecise CFS scoring is possible [66], there is evidence that the CFS has acceptable interindividual variation in the critically ill population and is validated to stratify older adults according to the level of vulnerability [39] and predict poor short and longer-term outcomes in critically ill patients $[5,8,67,68]$.

\section{Conclusions}

In this multinational individual patient data meta-analysis, almost two-thirds of frail patients with COVID-19 who were admitted to ICU died in hospital. Frail patients spent a shorter amount of time in ICU suggesting decisions to limit life-sustaining treatments play a role in our findings. Frailty captures risks beyond other known risk factors in those with COVID-19 admitted to the ICU. Future studies should consider incorporating frailty into the patient assessment process alongside other commonly used measures (age, sex, comorbidities, illness acuity) to support clinicians in making better decisions for severe forms of COVID19

\section{Declarations}

Funding: No funding sources to declare

Competing interests/competing interests: All authors declare no support from any organization for the submitted work, no competing interests with regards to the submitted work

Availability of data and material: A few authors provided individual patient data to conduct this meta-analysis

Code availability: not applicable

Ethics Approval: Not applicable

Consent to participate: Not applicable

Consent for publication: Not applicable

\section{References}

1. Definition of older or elderly person.

2. Rechel B, Grundy E, Robine JM, Cylus J, Mackenbach JP, Knai C, McKee M. Ageing in the European Union. Lancet. 2013;381(9874):1312-22.

3. Bagshaw SM, Webb SA, Delaney A, George C, Pilcher D, Hart GK, Bellomo R. Very old patients admitted to intensive care in Australia and New Zealand: a multi-centre cohort analysis. Crit Care. 2009;13(2):R45.

4. Nguyen YL, Angus DC, Boumendil A, Guidet B. The challenge of admitting the very elderly to intensive care. Ann Intensive Care. 2011;1(1):29.

5. Fisher C, Karalapillai DK, Bailey M, Glassford NG, Bellomo R, Jones D. Predicting intensive care and hospital outcome with the Dalhousie Clinical Frailty Scale: a pilot assessment. Anaesth Intensive Care. 2015;43(3):361-8.

6. Clegg A, Young J, lliffe S, Rikkert MO, Rockwood K. Frailty in elderly people. Lancet. 2013;381(9868):752-62.

7. Flaatten H, De Lange DW, Morandi A, Andersen FH, Artigas A, Bertolini G, Boumendil A, Cecconi M, Christensen S, Faraldi L, et al. The impact of frailty on ICU and 30-day mortality and the level of care in very elderly patients ( $>/=80$ years). Intensive Care Med. 2017;43(12):1820-8.

8. Bagshaw SM, Stelfox HT, McDermid RC, Rolfson DB, Tsuyuki RT, Baig N, Artiuch B, Ibrahim Q, Stollery DE, Rokosh E, et al. Association between frailty and short- and long-term outcomes among critically ill patients: a multicentre prospective cohort study. CMAJ. 2014;186(2):E95-102.

9. Darvall JN, Bellomo R, Paul E, Subramaniam A, Santamaria JD, Bagshaw SM, Rai S, Hubbard RE, Pilcher D. Frailty in very old critically ill patients in Australia and New Zealand: a population-based cohort study. Med J Aust. 2019;211(7):318-23.

10. Muscedere J, Waters B, Varambally A, Bagshaw SM, Boyd JG, Maslove D, Sibley S, Rockwood K. The impact of frailty on intensive care unit outcomes: a systematic review and meta-analysis. Intensive Care Med. 2017;43(8):1105-22.

11. Wu C, Chen X, Cai Y, Xia J, Zhou X, Xu S, Huang H, Zhang L, Zhou X, Du C, et al: Risk Factors Associated With Acute Respiratory Distress Syndrome and Death in Patients With Coronavirus Disease 2019 Pneumonia in Wuhan, China. JAMA Intern Med 2020.

12. Ciceri F, Beretta L, Scandroglio AM, Colombo S, Landoni G, Ruggeri A, Peccatori J, D'Angelo A, De Cobelli F, Rovere-Querini P, et al. Microvascular COVID-19 lung vessels obstructive thromboinflammatory syndrome (MicroCLOTS): an atypical acute respiratory distress syndrome working hypothesis. Crit Care Resusc. 2020;22(2):95-7.

13. Phua J, Weng L, Ling L, Egi M, Lim CM, Divatia JV, Shrestha BR, Arabi YM, Ng J, Gomersall CD, et al: Intensive care management of coronavirus disease 2019 (COVID-19): challenges and recommendations. Lancet Respir Med 2020.

14. Abate SM, Ahmed Ali S, Mantfardo B, Basu B: Rate of Intensive Care Unit admission and outcomes among patients with coronavirus: A systematic review and Meta-analysis. PLoS One 2020, 15(7):e0235653.

15. Lim ZJ, Subramaniam A, Reddy MP, Blecher G, Kadam U, Afroz A, Billah B, Ashwin S, Kubicki M, Bilotta F, et al: Case Fatality Rates for CoVID-19 Patients Requiring Invasive Mechanical Ventilation: A Meta-analysis. Am J Respir Crit Care Med 2020. 
16. Dennis JM, McGovern AP, Vollmer SJ, Mateen BA. Improving Survival of Critical Care Patients With Coronavirus Disease 2019 in England: A National Cohort Study, March to June 2020*. Critical Care Medicine 2021, 49(2).

17. Seligman B, Charest B, Gagnon DR, Orkaby AR. Trends in 30-day mortality from COVID-19 among older adults in the Veterans Affairs system. J Am Geriatr Soc. 2021;69(6):1448-50.

18. Excellence, NIfHaC: COVID-19 rapid guideline: critical care in adults. 2020.

19. Azoulay E, Beloucif S, Guidet B, Pateron D, Vivien B, Le Dorze M. Admission decisions to intensive care units in the context of the major CoVID-19 outbreak: local guidance from the COVID-19 Paris-region area. Crit Care. 2020;24(1):293.

20. Moher D, Liberati A, Tetzlaff J, Altman DG, Group P. Preferred reporting items for systematic reviews and meta-analyses: the PRISMA statement. BMJ. 2009;339:b2535.

21. Living. Evidence on COVID-19 https://ispmbern.github.io/covid-19/living-review/.

22. Apea VJ, Wan YI, Dhairyawan R, Puthucheary ZA, Pearse RM, Orkin CM, Prowle JR. Ethnicity and outcomes in patients hospitalised with COVID-19 infection in East London: an observational cohort study. BMJ Open. 2021;11(1):e042140.

23. Aw D, Woodrow L, Ogliari G, Harwood R. Association of frailty with mortality in older inpatients with Covid-19: a cohort study. Age Ageing. 2020;49(6):915-22.

24. Brill SE, Jarvis HC, Ozcan E, Burns TLP, Warraich RA, Amani LJ, Jaffer A, Paget S, Sivaramakrishnan A, Creer DD. COVID-19: a retrospective cohort study with focus on the over-80s and hospital-onset disease. BMC Med. 2020;18(1):194.

25. Chinnadurai R, Ogedengbe O, Agarwal P, Money-Coomes S, Abdurrahman AZ, Mohammed S, Kalra PA, Rothwell N, Pradhan S. Older age and frailty are the chief predictors of mortality in COVID-19 patients admitted to an acute medical unit in a secondary care setting- a cohort study. BMC Geriatr. 2020;20(1):409.

26. De Smet R, Mellaerts B, Vandewinckele H, Lybeert P, Frans E, Ombelet S, Lemahieu W, Symons R, Ho E, Frans J, et al. Frailty and Mortality in Hospitalized Older Adults With COVID-19: Retrospective Observational Study. J Am Med Dir Assoc. 2020;21(7):928-32 e921.

27. Fagard K, Gielen E, Deschodt M, Devriendt E, Flamaing J. Risk factors for severe COVID-19 disease and death in patients aged 70 and over: a retrospective observational cohort study. Acta Clin Belg 2021:1-8.

28. Hoek RAS, Manintveld OC, Betjes MGH, Hellemons ME, Seghers L, Van Kampen JAA, Caliskan K, van de Wetering J, van den Hoogen M, Metselaar HJ, et al. COVID-19 in solid organ transplant recipients: a single-center experience. Transpl Int. 2020;33(9):1099-105.

29. Koduri G, Gokaraju S, Darda M, Warrier V, Duta I, Hayes F, Sayed IE, Ahmed Y. Clinical characteristics and Outcomes of 500 patients with CoVID Pneumonia - Results from a Single center (Southend University Hospital). medRxiv 2020:2020.2008.2013.20163030.

30. Kokoszka-Bargieł I, Cyprys P, Rutkowska K, Madowicz J, Knapik P. Intensive Care Unit Admissions During the First 3 Months of the COVID-19 Pandemic in Poland: A Single-Center, Cross-Sectional Study. Med Sci Monit. 2020;26:e926974.

31. Lim JP, Low KYH, Lin NJJ, Lim CZQ, Ong SWX, Tan WYT, Tay WC, Tan HN, Young BE, Lye DCB, et al. Predictors for development of critical illness amongst older adults with COVID-19: Beyond age to age-associated factors. Arch Gerontol Geriatr. 2021;94:104331.

32. Marengoni A, Zucchelli A, Grande G, Fratiglioni L, Rizzuto D. The impact of delirium on outcomes for older adults hospitalised with COVID-19. Age Ageing. 2020;49(6):923-6.

33. Owen RK, Conroy SP, Taub N, Jones W, Bryden D, Pareek M, Faull C, Abrams KR, Davis D, Banerjee J. Comparing associations between frailty and mortality in hospitalised older adults with or without COVID-19 infection: a retrospective observational study using electronic health records. Age Ageing. 2021;50(2):307-16

34. Poco PCE, Aliberti MJR, Dias MB, Takahashi SF, Leonel FC, Altona M, Azevedo ALV, Shin-Ike IA, Garcia BA, Sumita LH, et al: Divergent: age, frailty, and atypical presentations of COVID-19 in hospitalized patients. J Gerontol A Biol Sci Med Sci 2020.

35. Tehrani S, Killander A, Astrand P, Jakobsson J, Gille-Johnson P. Risk factors for death in adult COVID-19 patients: Frailty predicts fatal outcome in older patients. Int J Infect Dis. 2021;102:415-21.

36. Welch C. Geriatric Medicine Research and Collaborative: Age and Frailty Are Independently Associated with Increased Mortality in COVID-19: Results of an International Multi-Centre Study.. In.; 2020.

37. Aliberti MJR, Szlejf C, Avelino-Silva VI, Suemoto CK, Apolinario D, Dias MB, Garcez FB, Trindade CB, Amaral J, de Melo LR, et al. COVID-19 is not over and age is not enough: Using frailty for prognostication in hospitalized patients. J Am Geriatr Soc. 2021;69(5):1116-27.

38. Lim JP, Low KYH, Lin NJJ, Lim CZQ, Ong SWX, Tan WYT, Tay WC, Tan HN, Young BE, Lye DCB, et al. Predictors for development of critical illness amongst older adults with COVID-19: Beyond age to age-associated factors. Arch Gerontol Geriatr. 2020;94:104331.

39. Rockwood K, Song X, MacKnight C, Bergman H, Hogan DB, McDowell I, Mitnitski A. A global clinical measure of fitness and frailty in elderly people. CMAJ. 2005;173(5):489-95.

40. Bagshaw M, Majumdar SR, Rolfson DB, Ibrahim Q, McDermid RC, Stelfox HT. A prospective multicenter cohort study of frailty in younger critically ill patients. Crit Care. 2016;20(1):175.

41. Fine JP, Gray RJ. A Proportional Hazards Model for the Subdistribution of a Competing Risk. J Am Stat Assoc. 1999;94(446):496-509.

42. Bravata DM, Perkins AJ, Myers LJ, Arling G, Zhang Y, Zillich AJ, Reese L, Dysangco A, Agarwal R, Myers J, et al. Association of Intensive Care Unit Patient Load and Demand With Mortality Rates in US Department of Veterans Affairs Hospitals During the COVID-19 Pandemic. JAMA Network Open.

2021;4(1):e2034266-6.

43. Burrell AJ, Pellegrini B, Salimi F, Begum H, Broadley T, Campbell LT, Cheng AC, Cheung W, Cooper DJ, Earnest A, et al. Outcomes for patients with COVID-19 admitted to Australian intensive care units during the first four months of the pandemic. Med J Aust. 2021;214(1):23-30.

Page $7 / 17$ 
44. Kundi H, Cetin EHO, Canpolat U, Aras S, Celik O, Ata N, Birinci S, Cay S, Ozeke O, Tanboga IH, et al. The role of Frailty on Adverse Outcomes Among Older Patients with COVID-19. J Infect. 2020;81(6):944-51.

45. Oliveira E, Parikh A, Lopez-Ruiz A, Carrilo M, Goldberg J, Cearras M, Fernainy K, Andersen S, Mercado L, Guan J, et al. ICU outcomes and survival in patients with severe COVID-19 in the largest health care system in central Florida. PLOS ONE. 2021;16(3):e0249038.

46. Baker KF, Hanrath AT, van der Loeff IS, Tee SA, Capstick R, Marchitelli G, Li A, Barr A, Eid A, Ahmed S, et al: CoVID-19 management in a UK NHS Foundation Trust with a High Consequence Infectious Diseases centre: a detailed descriptive analysis. medRxiv 2020:2020.2005.2014.20100834.

47. Bhatraju PK, Ghassemieh BJ, Nichols M, Kim R, Jerome KR, Nalla AK, Greninger AL, Pipavath S, Wurfel MM, Evans L, et al. Covid-19 in Critically III Patients in the Seattle Region - Case Series. N Engl J Med. 2020;382(21):2012-22.

48. Arentz M, Yim E, Klaff L, Lokhandwala S, Riedo FX, Chong M, Lee M. Characteristics and Outcomes of 21 Critically III Patients With COVID-19 in Washington State. Jama. 2020;323(16):1612-4.

49. Wang Y, Lu X, Li Y, Chen H, Chen T, Su N, Huang F, Zhou J, Zhang B, Yan F, et al. Clinical Course and Outcomes of 344 Intensive Care Patients with COVID19. Am J Respir Crit Care Med. 2020;201(11):1430-4.

50. Cummings MJ, Baldwin MR, Abrams D, Jacobson SD, Meyer BJ, Balough EM, Aaron JG, Claassen J, Rabbani LE, Hastie J, et al. Epidemiology, clinical course, and outcomes of critically ill adults with COVID-19 in New York City: a prospective cohort study. Lancet. 2020;395(10239):1763-70.

51. Asch DA. Opening Hospitals to More Patients During the COVID-19 Pandemic-Making It Safe and Making It Feel Safe. JAMA Internal Medicine. 2020;180(8):1048-9.

52. Bellelli G, Rebora P, Citerio G. The role of frailty in COVID-19 patients. Intensive Care Med. 2020;46(10):1958-9.

53. Jung C, Flaatten H, Fjølner J, Bruno RR, Wernly B, Artigas A, Bollen Pinto B, Schefold JC, Wolff G, Kelm M, et al. The impact of frailty on survival in elderly intensive care patients with COVID-19: the COVIP study. Crit Care. 2021;25(1):149.

54. Zhang X-M, Jiao J, Cao J, Huo X-P, Zhu C, Wu X-J, Xie X-H. Frailty as a predictor of mortality among patients with COVID-19: a systematic review and meta-analysis. BMC Geriatrics. 2021;21(1):186.

55. Okahara S, Subramaniam A, Darvall JN, Ueno R, Bailey M, Pilcher DV. The Relationship between Frailty and Mechanical Ventilation: A Population-based Cohort Study. Ann Am Thorac Soc 2021.

56. Darvall JN, Bellomo R, Bailey M, Paul E, Young PJ, Rockwood K, Pilcher D. Frailty and outcomes from pneumonia in critical illness: a population-based cohort study. Br J Anaesth. 2020;125(5):730-8.

57. Zhang X, Dou Q, Zhang W, Wang C, Xie X, Yang Y, Zeng Y. Frailty as a Predictor of All-Cause Mortality Among Older Nursing Home Residents: A Systematic Review and Meta-analysis. J Am Med Dir Assoc. 2019;20(6):657-63 e654.

58. Chang SF, Lin HC, Cheng CL. The Relationship of Frailty and Hospitalization Among Older People: Evidence From a Meta-Analysis. J Nurs Scholarsh. 2018;50(4):383-91.

59. Zhao F, Tang B, Hu C, Wang B, Wang Y, Zhang L. The impact of frailty on posttraumatic outcomes in older trauma patients: A systematic review and metaanalysis. J Trauma Acute Care Surg. 2020;88(4):546-54.

60. Chong E, Chan M, Tan HN, Lim WS. COVID-19: Use of the Clinical Frailty Scale for Critical Care Decisions. J Am Geriatr Soc. 2020;68(6):E30-2.

61. Ho EP, Neo HY. COVID 19: prioritise autonomy, beneficence and conversations before score-based triage. Age Ageing. 2021;50(1):11-5.

62. Hubbard RE, Maier AB, Hilmer SN, Naganathan V, Etherton-Beer C, Rockwood K. Frailty in the face of COVID-19. Age Ageing. 2020;49(4):499-500.

63. Supady A, Curtis JR, Abrams D, Lorusso R, Bein T, Boldt J, Brown CE, Duerschmied D, Metaxa V, Brodie D. Allocating scarce intensive care resources during the COVID-19 pandemic: practical challenges to theoretical frameworks. Lancet Respir Med. 2021;9(4):430-4.

64. Supady A, Brodie D, Curtis JR. Ten things to consider when implementing rationing guidelines during a pandemic. Intensive Care Med. 2021;47(5):605-8.

65. Subramaniam A, Tiruvoipati R, Green C, Srikanth V, Hussain F, Soh L, Yeoh AC, Bailey M, Pilcher D. Frailty status, timely goals of care documentation and clinical outcomes in older hospitalised medical patients. Intern Med $\mathrm{J} 2020$.

66. Darvall JN, Boonstra T, Norman J, Murphy D, Bailey M, Iwashyna TJ, Bagshaw SM, Bellomo R. Retrospective frailty determination in critical illness from a review of the intensive care unit clinical record. Anaesth Intensive Care. 2019;47(4):343-8.

67. Bagshaw SM, Stelfox HT, Johnson JA, McDermid RC, Rolfson DB, Tsuyuki RT, Ibrahim Q, Majumdar SR. Long-term association between frailty and healthrelated quality of life among survivors of critical illness: a prospective multicenter cohort study. Crit Care Med. 2015;43(5):973-82.

68. Le Maguet P, Roquilly A, Lasocki S, Asehnoune K, Carise E, Saint Martin M, Mimoz O, Le Gac G, Somme D, Cattenoz C, et al. Prevalence and impact of frailty on mortality in elderly ICU patients: a prospective, multicenter, observational study. Intensive Care Med. 2014;40(5):674-82.

\section{Tables}


Table 1

Demographics of Patients with COVID-19 admitted to ICU based on whether the patients survived or died. Data are summarized according to distribution if normal (Mean [SD]), non-normal (Median [IQR]), Categorical and Binary (Number [\%]).

\begin{tabular}{|c|c|c|c|}
\hline Characteristics & Survivors & Non-survivors & p-value* \\
\hline Number & 918 & 1083 & - \\
\hline \multicolumn{4}{|l|}{ General Demographics } \\
\hline Male sex (\%) & $554(50.2 \%)$ & $508(55.3 \%)$ & 0.025 \\
\hline Age (years) (mean (SD)) & $67.1(11.0)$ & $61.4(11.9)$ & $<0.001$ \\
\hline \multicolumn{4}{|l|}{ Age categories } \\
\hline$-<50$ years & $38(4.1 \%)$ & $143(13.2 \%)$ & $<0.001$ \\
\hline$-50-64.9$ years & $325(35.4 \%)$ & 497 (45.9\%) & $<0.001$ \\
\hline - $65-74.9$ years & $351(38.2 \%)$ & $315(38.4 \%)$ & $<0.001$ \\
\hline$-\geq 75$ years & $204(22.2 \%)$ & $128(11.8 \%)$ & $<0.001$ \\
\hline \multicolumn{4}{|l|}{ Admission source } \\
\hline - Home & $195(87.8 \%)$ & $392(91.8 \%)$ & 0.12 \\
\hline - 24-hour long-term facility & $15(6.8 \%)$ & $4(0.9 \%)$ & 0.001 \\
\hline - Other & $12(5.4 \%)$ & $31(7.3 \%)$ & 0.41 \\
\hline \multicolumn{4}{|l|}{ Smoking status } \\
\hline Current smoker & $183(27.7 \%)$ & $181(28.9 \%)$ & \multirow[t]{2}{*}{0.67} \\
\hline Ex or non-smoker & $477(72.3 \%)$ & $445(71.2 \%)$ & \\
\hline \multicolumn{4}{|l|}{ Documented co-morbidities } \\
\hline - Hypertension & $465(67.1 \%)$ & $448(69.1 \%)$ & 0.45 \\
\hline - Cardiovascular disease & $203(22.5 \%)$ & $179(17.2 \%)$ & 0.003 \\
\hline - Cerebrovascular accident & $60(8.7 \%)$ & $39(6.0 \%)$ & 0.08 \\
\hline - Active cancer & $121(13.6 \%)$ & $101(9.7 \%)$ & 0.008 \\
\hline - Chronic respiratory disease ${ }^{\star *}$ & $147(16.1 \%)$ & $171(15.9 \%)$ & 0.95 \\
\hline - Obesity (BMI $\geq 30 \mathrm{~kg} \cdot \mathrm{m}^{-2}$ ) & $215(26.1 \%)$ & $363(38.5 \%)$ & $<0.001$ \\
\hline - Chronic kidney disease & $130(19.5 \%)$ & $82(13.4 \%)$ & 0.004 \\
\hline - Diabetes mellitus & $413(45.1 \%)$ & $410(38.1 \%)$ & 0.002 \\
\hline - Dementia & $34(3.8 \%)$ & $18(1.7 \%)$ & 0.007 \\
\hline Charlson comorbidity index (median (IQR)) & $2(1,4)$ & $1(0,3)$ & $<0.001$ \\
\hline Number of co-morbidities $\leq 2$ & $222(29.6 \%)$ & $231(22.6 \%)$ & \multirow[t]{2}{*}{0.018} \\
\hline Number of co-morbidities > 2 & $527(70.4 \%)$ & $713(75.5 \%)$ & \\
\hline Clinical frailty scale (median (IQR)) & $3(3,5)$ & $3(2,4)$ & $<0.001$ \\
\hline \multicolumn{4}{|l|}{ Illness severity scores } \\
\hline APACHE 2 (median (IQR)) & $14(6,23)$ & $14(9,23)$ & 0.07 \\
\hline APACHE 3 (median (IQR)) & No data & No data & - \\
\hline SAPS 2 (median (IQR)) & $38(24,56)$ & $41(30,57)$ & 0.006 \\
\hline SOFA (median (IQR)) & $7(5,12)$ & $8(5,12)$ & 0.09 \\
\hline \multicolumn{4}{|l|}{ Symptoms, n (\%) } \\
\hline Respiratory & 776 (91.2\%) & 897 (91.4\%) & 0.93 \\
\hline Sputum & $25(4.1 \%)$ & $24(4.5 \%)$ & 0.77 \\
\hline Fever & $474(55.8 \%)$ & $630(64.2 \%)$ & $<0.001$ \\
\hline Lethargy / Myalgia & $254(40.5 \%)$ & $259(46.8 \%)$ & 0.030 \\
\hline
\end{tabular}




\begin{tabular}{|c|c|c|c|}
\hline Characteristics & Survivors & Non-survivors & p-value* \\
\hline Delirium & $98(11.6 \%)$ & $100(10.2 \%)$ & 0.37 \\
\hline Gastrointestinal & $75(11.9 \%)$ & $72(13.0 \%)$ & 0.60 \\
\hline Symptom time (days) & $7(5,11)$ & $8(5,10)$ & 0.35 \\
\hline Time to ICU (hours) & $3(2,4)$ & $3(2,5)$ & 0.97 \\
\hline \multicolumn{4}{|c|}{ Pathology results (first 24hrs), median (IQR) } \\
\hline \multicolumn{4}{|l|}{ Acid base status } \\
\hline $\mathrm{pH}$ & $7.36(0.12)$ & $7.40(0.09)$ & $<0.001$ \\
\hline $\mathrm{PaO}_{2}(\mathrm{mmHg})$ & $77(36)$ & $78(35)$ & 0.68 \\
\hline $\mathrm{PaCO}_{2}(\mathrm{mmHg})$ & $42(14)$ & $39(11)$ & 0.003 \\
\hline $\mathrm{HCO}_{3}(\mathrm{mmol} / \mathrm{l})$ & $23(5)$ & $24(4)$ & $<0.001$ \\
\hline $\mathrm{SaO}_{2}$ & $90(10)$ & $91(9)$ & 0.87 \\
\hline L-lactate (mmol/l) & $13(7,18)$ & $9(2,15)$ & $<0.001$ \\
\hline \multicolumn{4}{|l|}{ Biochemistry } \\
\hline CRP & $167(84,268)$ & $138(66,236)$ & $<0.001$ \\
\hline Urea & $54(18,102)$ & $26(7,55)$ & $<0.001$ \\
\hline Creatinine & $113(80,203)$ & $90(70,141)$ & $<0.001$ \\
\hline LDH & $501(384,666)$ & $431(321,547)$ & $<0.001$ \\
\hline D-dimer & $2.36(1.09,7.34)$ & $1.37(0.65,3.63)$ & $<0.001$ \\
\hline Troponin & $0.03(0.01,0.07)$ & $0.02(0.00,0.03)$ & $<0.001$ \\
\hline \multicolumn{4}{|l|}{ Haematology } \\
\hline Neutrophils & $8.2(5.4,12.6)$ & $7.1(4.8,10.5)$ & $<0.001$ \\
\hline Lymphocytes & $0.75(0.50,1.10)$ & $0.89(0.60,1.20)$ & $<0.001$ \\
\hline $\mathrm{N}-\mathrm{L}$ ratio & $10.8(6.2,19.0)$ & $8.0(4.8,14.3)$ & $<0.001$ \\
\hline Platelets & $203(146,278)$ & $221(165,306)$ & $<0.001$ \\
\hline \multicolumn{4}{|l|}{ Radiology } \\
\hline Abnormal CXR & $672(73.2 \%)$ & $850(78.5 \%)$ & 0.003 \\
\hline \multicolumn{4}{|l|}{ Illness severity scores } \\
\hline APACHE II & $19(9,25)$ & $10(5,19)$ & $<0.001$ \\
\hline SAPS 2 & $47(30,62)$ & $31(24,47)$ & $<0.001$ \\
\hline SOFA & $9(6,13)$ & $6(4,9)$ & $<0.001$ \\
\hline \multicolumn{4}{|l|}{ Outcome data } \\
\hline ICU LOS (days) & $11(6,19)$ & $10(5,19)$ & 0.14 \\
\hline Hospital LOS (days) & $13(8,21)$ & $19(12,32)$ & $<0.001$ \\
\hline \multicolumn{4}{|l|}{ Organ Support } \\
\hline HFNC & $31(79.5 \%)$ & $42(73.7 \%)$ & 0.629 \\
\hline CPAP & $176(27.0 \%)$ & $241(40.4 \%)$ & $<0.001$ \\
\hline IMV & $609(66.3 \%)$ & $405(37.4 \%)$ & $<0.001$ \\
\hline IMV (days) & $12(7,19)$ & $9(5,16)$ & $<0.001$ \\
\hline Dialysis & $311(45.3 \%)$ & 98 (15.2\%) & $<0.001$ \\
\hline Vasopressors & 550 (84.8\%) & 275 (46.8\%) & $<0.001$ \\
\hline
\end{tabular}

SD - standard deviation, IQR - interquartile range, IHD - ischemic heart disease, CVD - cardiovascular disease, COPD - chronic obstructive pulmonary disease, BMI - body mass index, APACHE - Acute Physiology and Chronic Health Evaluation, SAPS - Simplified Acute Physiology Score, SOFA - Sequential Organ 
Failure Score, $\mathrm{PaO}_{2}$ - partial pressure of oxygen, $\mathrm{PaCO}_{2}$ - partial pressure of carbon dioxide, $\mathrm{SaO}_{2}$ - arterial oxygen saturation, $\mathrm{CRP}$ - C-reactive protein, WCC white cell count, N-L - neutrophil-lymphocyte ratio, LDH - lactate dehydrogenase, CXR - chest X-ray

* Some of the results will be statistically significant because of the large sample size but may not be clinically significant.

${ }^{* *}$ COPD and/or asthma 
Table 2

Multivariable analysis: Outcome variable is hospital mortality $(0=$ Survival, $1=$ Death)

\begin{tabular}{|c|c|c|c|c|}
\hline \multirow[t]{2}{*}{ Variable } & \multicolumn{2}{|l|}{ Initial model } & \multicolumn{2}{|l|}{ Final model } \\
\hline & OR (95\% Cl) & p-value & OR $(95 \% \mathrm{Cl})$ & p-value \\
\hline \multirow[t]{2}{*}{ Age } & 1.06 & $<0.001$ & 1.06 & $<0.001$ \\
\hline & $(1.04,1.08)$ & & $(1.04,1.08)$ & \\
\hline \multirow[t]{2}{*}{ Hypertension } & 0.62 & 0.006 & 0.64 & 0.008 \\
\hline & $(0.44,0.89)$ & & $(0.46,0.89)$ & \\
\hline \multirow[t]{2}{*}{ Diabetes Mellitus } & 1.12 & 0.46 & - & - \\
\hline & $(0.82,1.53)$ & & & \\
\hline \multirow[t]{2}{*}{ APACHE-2 } & 0.99 & 0.81 & - & - \\
\hline & $(0.97,1.02)$ & & & \\
\hline \multirow[t]{2}{*}{ SOFA } & 1.04 & 0.17 & 1.05 & 0.024 \\
\hline & $(0.98,1.11)$ & & $(1.01,1.09)$ & \\
\hline \multirow[t]{2}{*}{ IMV } & 3.74 & $<0.001$ & 3.87 & $<0.001$ \\
\hline & $(2.36,5.92)$ & & $(2.47,6.06)$ & \\
\hline \multirow[t]{2}{*}{ Dialysis } & 3.75 & $<0.001$ & 3.95 & $<0.001$ \\
\hline & $(2.62,5.33)$ & & $(2.79,5.60)$ & \\
\hline \multirow[t]{2}{*}{ Vasopressors } & 3.32 & $<0.001$ & 3.19 & $<0.001$ \\
\hline & $(2.27,4.87)$ & & $(2.19,4.64)$ & \\
\hline \multirow[t]{2}{*}{$\mathrm{pH}$} & 0.40 & 0.36 & - & - \\
\hline & $(0.06,2.79)$ & & & \\
\hline \multirow[t]{2}{*}{ Lactate } & 1.03 & 0.013 & 1.03 & 0.008 \\
\hline & $(1.01,1.05)$ & & $(1.01,1.05)$ & \\
\hline \multicolumn{5}{|l|}{ CFS Level } \\
\hline \multirow[t]{2}{*}{1} & 1.00 & Reference & 1.00 & Reference \\
\hline & & Level & & Level \\
\hline \multirow[t]{2}{*}{2} & 1.41 & 0.63 & 1.45 & 0.36 \\
\hline & $(0.63,3.15)$ & & $(0.66,3.19)$ & \\
\hline \multirow[t]{2}{*}{3} & 1.47 & 0.33 & 1.50 & 0.29 \\
\hline & $(0.68,3.15)$ & & $(0.71,3.19)$ & \\
\hline \multirow[t]{2}{*}{4} & 2.99 & 0.008 & 3.26 & 0.004 \\
\hline & $(1.32,6.77)$ & & $(1.46,7.29)$ & \\
\hline \multirow[t]{2}{*}{5} & 3.54 & 0.004 & 3.86 & 0.002 \\
\hline & $(1.48,8.47)$ & & $(1.63,9.13)$ & \\
\hline \multirow[t]{2}{*}{6} & 3.44 & 0.010 & 3.67 & 0.006 \\
\hline & $(1.35,8.80)$ & & $(1.46,9.23)$ & \\
\hline \multirow[t]{2}{*}{7} & 4.52 & 0.003 & 4.73 & 0.002 \\
\hline & $(1.64,12.41)$ & & $(1.73,12.90)$ & \\
\hline \multirow[t]{2}{*}{8} & 8.85 & 0.028 & 16.56 & 0.005 \\
\hline & $(1.26,62.18)$ & & $(2.82,120.04)$ & \\
\hline
\end{tabular}

APACHE - Acute Physiology and Chronic Health Evaluation, SOFA - Sequential Organ Failure Score, IMV - invasive mechanical ventilation, CFS - clinical frailty scale 
Table 3

Demographics of Patients with COVID-19 admitted to ICU based on frailty status.

\begin{tabular}{|c|c|c|c|}
\hline Characteristics & Non-Frail & Frail & p-value* \\
\hline Number & 1613 & 388 & - \\
\hline \multicolumn{4}{|l|}{ General Demographics } \\
\hline Male sex (\%) & $870(54 \%)$ & $182(47 \%)$ & 0.008 \\
\hline Age (years) (mean (SD)) & $62.5(11.3)$ & $70.1(11.9)$ & $<0.001$ \\
\hline \multicolumn{4}{|l|}{ Age categories } \\
\hline$-<50$ years & $164(10.2 \%$ & $17(4.4 \%)$ & $<0.001$ \\
\hline$-50-64.9$ years & $731(45.3 \%)$ & $91(23.4 \%)$ & $<0.001$ \\
\hline$-65-74.9$ years & $516(32.0 \%)$ & $150(38.7 \%)$ & 0.001 \\
\hline$-\geq 75$ years & $202(12.5 \%)$ & $130(33.5 \%)$ & $<0.001$ \\
\hline \multicolumn{4}{|l|}{ Admission source } \\
\hline - Home & $506(90.5 \%)$ & $81(90.0 \%)$ & 0.85 \\
\hline - 24-hour long-term facility & $11(2.0 \%)$ & $8(8.8 \%)$ & 0.002 \\
\hline - Other & $42(7.5 \%)$ & $1(1.1 \%)$ & 0.020 \\
\hline \multicolumn{4}{|l|}{ Smoking status } \\
\hline Current smoker & $287(28.9 \%)$ & $77(26.3 \%)$ & \multirow[t]{2}{*}{0.42} \\
\hline Ex or non-smoker & 707 (71.1\%) & $215(73.6 \%)$ & \\
\hline \multicolumn{4}{|l|}{ Documented co-morbidities } \\
\hline - Hypertension & $693(66.4 \%)$ & $220(73.8 \%)$ & 0.017 \\
\hline - Cardiovascular disease & $241(15.5 \%)$ & $141(36.4 \%)$ & $<0.001$ \\
\hline - Cerebrovascular accident & $46(4.4 \%)$ & $53(17.7 \%)$ & $<0.001$ \\
\hline - Active cancer & $133(8.6 \%)$ & $89(23.0 \%)$ & $<0.001$ \\
\hline - Chronic respiratory disease $e^{* *}$ & $251(15.7 \%)$ & $67(17.2 \%)$ & 0.44 \\
\hline - Obesity $\left(\mathrm{BMI} \geq 30 \mathrm{~kg} \cdot \mathrm{m}^{-2}\right)$ & $496(35.1 \%)$ & $82(23.0 \%)$ & $<0.001$ \\
\hline - Chronic kidney disease & $134(13.7 \%)$ & $78(26.2 \%)$ & $<0.001$ \\
\hline - Diabetes mellitus & $643(40.1 \%)$ & $180(46.4 \%)$ & 0.025 \\
\hline - Dementia & $11(0.7 \%)$ & $41(10.6 \%)$ & $<0.001$ \\
\hline Charlson comorbidity index (median (IQR)) & $1(0,3)$ & $3(1,6)$ & $<0.001$ \\
\hline No comorbidities & $237(14.7 \%)$ & $71(18.3 \%)$ & \multirow[t]{3}{*}{0.002} \\
\hline Number of co-morbidities $\leq 2$ & $390(24.2 \%)$ & $63(16.2 \%)$ & \\
\hline Number of co-morbidities $>2$ & $986(61.1 \%)$ & $254(65.5 \%)$ & \\
\hline Clinical frailty scale (median (IQR)) & $3(2,3)$ & $6(5,6)$ & $<0.001$ \\
\hline \multicolumn{4}{|l|}{ Illness severity scores } \\
\hline APACHE 2 (median (IQR)) & $14(6,23)$ & $14(9,23)$ & 0.07 \\
\hline APACHE 3 (median (IQR)) & No data & No data & - \\
\hline SAPS 2 (median (IQR)) & $38(24,56)$ & $41(30,57)$ & 0.006 \\
\hline SOFA (median (IQR)) & $7(5,12)$ & $8(5,12)$ & 0.09 \\
\hline \multicolumn{4}{|l|}{ Symptoms, n (\%) } \\
\hline Respiratory & $1344(91.7 \%)$ & $329(89.9 \%)$ & 0.25 \\
\hline Sputum & $35(4.0 \%)$ & $14(5.2 \%)$ & 0.39 \\
\hline Fever & $921(62.9 \%)$ & $183(50.0 \%)$ & $<0.001$ \\
\hline Lethargy / Myalgia & $416(45.9 \%)$ & $97(35.0 \%)$ & 0.001 \\
\hline
\end{tabular}

Page 13/17 


\begin{tabular}{|c|c|c|c|}
\hline Characteristics & Non-Frail & Frail & p-value ${ }^{*}$ \\
\hline Delirium & $126(8.6 \%)$ & $72(19.8 \%)$ & $<0.001$ \\
\hline Gastrointestinal & $120(13.3 \%)$ & $27(9.8 \%)$ & 0.15 \\
\hline Symptom time (days) & $8(5,11)$ & $7(4,10)$ & 0.001 \\
\hline Time to ICU (hours) & $3(1,5)$ & $3(2,5)$ & 0.46 \\
\hline \multicolumn{4}{|c|}{ Pathology results (first 24hrs), median (IQR) } \\
\hline \multicolumn{4}{|l|}{ Acid base status } \\
\hline $\mathrm{pH}$ & $7.41(7.33,7.46)$ & $7.39(7.33,7.45)$ & 0.20 \\
\hline $\mathrm{PaO}_{2}(\mathrm{mmHg})$ & $70(60,84)$ & $73(59,90)$ & 0.18 \\
\hline $\mathrm{PaCO}_{2}(\mathrm{mmHg})$ & $38(33,46)$ & $38(32,44)$ & 0.42 \\
\hline $\mathrm{HCO}_{3}(\mathrm{mmol} / \mathrm{l})$ & $24(21,26)$ & $23(20,27)$ & 0.024 \\
\hline $\mathrm{SaO}_{2}$ & $93(89,96)$ & $94(90,96)$ & 0.023 \\
\hline L-lactate (mmol/l) & $11(2,16)$ & $12(7,18)$ & $<0.001$ \\
\hline \multicolumn{4}{|l|}{ Biochemistry } \\
\hline CRP & $154(78,248)$ & $144(52,260)$ & 0.11 \\
\hline Urea & $33(9,66)$ & $62(25,103)$ & $<0.001$ \\
\hline Creatinine & $97(71,164$ & $115(79,195)$ & 0.002 \\
\hline LDH & $471(365,629)$ & $433(316,551)$ & $<0.001$ \\
\hline D-dimer & $1670(784,5193)$ & $2116(1023,5861)$ & 0.002 \\
\hline Troponin & $0.08(0.02,8.00)$ & $0.05(0.03,0.16)$ & 0.044 \\
\hline \multicolumn{4}{|l|}{ Haematology } \\
\hline Neutrophils & $7.6(5.0,11.4)$ & $7.8(5.0,11.5)$ & 0.977 \\
\hline Lymphocytes & $0.83(0.57,1.19)$ & $0.72(0.47,1.1)$ & $<0.001$ \\
\hline $\mathrm{N}-\mathrm{L}$ ratio & $8.8(5.2,15.6)$ & $10.0(5.6,18.9)$ & 0.015 \\
\hline Platelets & $217(159,300)$ & $195(131,260)$ & $<0.001$ \\
\hline \multicolumn{4}{|l|}{ Radiology } \\
\hline Abnormal CXR & 1237 (76.7\%) & 285 (73.5\%) & 0.102 \\
\hline
\end{tabular}

SD - standard deviation, IQR - interquartile range, IHD - ischemic heart disease, CVD - cardiovascular disease, COPD - chronic obstructive pulmonary disease, BMI - body mass index, APACHE - Acute Physiology and Chronic Health Evaluation, SAPS - Simplified Acute Physiology Score, SOFA - Sequential Organ Failure Score, $\mathrm{PaO}_{2}$ - partial pressure of oxygen, $\mathrm{PaCO}_{2}$ - partial pressure of carbon dioxide, $\mathrm{SaO}_{2}$ - arterial oxygen saturation, $\mathrm{CRP}$ - C-reactive protein, WCC white cell count, N-L - neutrophil-lymphocyte ratio, LDH - lactate dehydrogenase, CXR - chest X-ray

* Some of the results will be statistically significant because of the large sample size but may not be clinically significant.

${ }^{* *}$ COPD and/or asthma 
Table 4

Unadjusted and adjusted (for age and sex) for ICU and hospital mortality (primary outcome) for patients among survivors and non-survivors who died after IC and duration of mechanical ventilation (secondary outcome; adjusted for age, chronic respiratory disease, chronic kidney disease, ischemic heart disease, admission source and APACHE 2 score), by CFS.

\begin{tabular}{|c|c|c|c|c|c|c|c|c|c|c|c|}
\hline \multirow[t]{2}{*}{$\begin{array}{l}\text { Clinical } \\
\text { frailty } \\
\text { scale }\end{array}$} & \multirow[t]{2}{*}{$\begin{array}{l}\text { Number } \\
\text { of } \\
\text { patients }\end{array}$} & \multirow{2}{*}{$\begin{array}{l}\text { ICU } \\
\text { mortality*, } \\
\text { n (\%) }\end{array}$} & \multirow{2}{*}{$\begin{array}{l}\text { Unadjusted } \\
\text { ICU } \\
\text { mortality, } \\
\text { OR (95\%- } \\
\text { Cl; p-value) }\end{array}$} & \multirow{2}{*}{$\begin{array}{l}\text { Adjusted } \\
\text { ICU } \\
\text { mortality, } \\
\text { OR (95\%- } \\
\text { Cl; p- } \\
\text { value) }\end{array}$} & \multirow{2}{*}{$\begin{array}{l}\text { Hospital } \\
\text { mortality } \\
\text { n (\%) }\end{array}$} & \multirow{2}{*}{$\begin{array}{l}\text { Unadjusted } \\
\text { Hospital } \\
\text { mortality, } \\
\text { OR (95\%- } \\
\text { Cl; p-value) }\end{array}$} & \multirow{2}{*}{$\begin{array}{l}\text { Adjusted } \\
\text { Hospital } \\
\text { mortality, } \\
\text { OR (95\%- } \\
\text { Cl; p- } \\
\text { value) }\end{array}$} & \multicolumn{2}{|c|}{$\begin{array}{l}\text { Duration of Mechanical } \\
\text { Ventilation among ICU } \\
\text { survivors (days) }\end{array}$} & \multicolumn{2}{|c|}{$\begin{array}{l}\text { Duration of Mechanice } \\
\text { Ventilation among tho } \\
\text { dying after ICU (days) }\end{array}$} \\
\hline & & & & & & & & $\begin{array}{l}\text { Unadjusted } \\
\text { geometric } \\
\text { mean } \\
(95 \%-\mathrm{Cl})\end{array}$ & $\begin{array}{l}\text { Adjusted } \\
\text { geometric } \\
\text { mean^ } \\
(95 \%-\mathrm{Cl})\end{array}$ & $\begin{array}{l}\text { Unadjusted } \\
\text { geometric } \\
\text { mean } \\
(95 \%-\mathrm{Cl})\end{array}$ & $\begin{array}{l}\text { Adjuste } \\
\text { geomet/ } \\
\text { mean }^{\wedge} \\
(95 \%-\mathrm{Cl}\end{array}$ \\
\hline \multirow[t]{2}{*}{1} & \multirow[t]{2}{*}{193} & \multirow{2}{*}{$\begin{array}{l}20 \\
(10.4 \%)\end{array}$} & \multirow[t]{2}{*}{ Reference } & \multirow[t]{2}{*}{ Reference } & \multirow{2}{*}{$\begin{array}{l}53 \\
(27.5 \%)\end{array}$} & \multirow[t]{2}{*}{ Reference } & \multirow[t]{2}{*}{ Reference } & 6.7 & 9.5 & 16.8 & 15.7 \\
\hline & & & & & & & & $(4.5,10.1)$ & $\begin{array}{l}(8.3 \\
10.7)\end{array}$ & $(13.1,15.6)$ & $\begin{array}{l}(14.3 \\
17.1)\end{array}$ \\
\hline \multirow[t]{2}{*}{2} & \multirow[t]{2}{*}{450} & \multirow{2}{*}{$\begin{array}{l}59 \\
(13.1 \%)\end{array}$} & 0.82 & 0.90 & \multirow{2}{*}{$\begin{array}{l}165 \\
(37.6 \%)\end{array}$} & 1.43 & 1.37 & 10.2 & 8.5 & 13.1 & 14.7 \\
\hline & & & $\begin{array}{l}(0.44,1.51 \\
\mathrm{p}=0.52)\end{array}$ & $\begin{array}{l}(0.48 \\
1.67 ; p= \\
0.73)\end{array}$ & & $\begin{array}{l}(0.98,2.06 \\
p=0.06)\end{array}$ & $\begin{array}{l}(0.94 \\
2.00 ; p= \\
0.10)\end{array}$ & $(8.9,12.0)$ & $(7.7,9.4)$ & $(11.0,15.6)$ & $\begin{array}{l}(13.5 \\
15.9)\end{array}$ \\
\hline \multirow[t]{2}{*}{3} & \multirow[t]{2}{*}{669} & \multirow{2}{*}{$\begin{array}{l}143 \\
(21.4 \%)\end{array}$} & 0.87 & 0.92 & \multirow{2}{*}{$\begin{array}{l}295 \\
(44.1 \%)\end{array}$} & 1.98 & 1.57 & 7.8 & 7.6 & 12.1 & 13.8 \\
\hline & & & $\begin{array}{l}(0.48,1.52 \\
p=0.58)\end{array}$ & $\begin{array}{l}(0.51 \\
1.64 ; p= \\
0.77)\end{array}$ & & $\begin{array}{l}(1.40,2.81 ; \\
p<0.001)\end{array}$ & $\begin{array}{l}(1.10 \\
2.25 ; p= \\
0.014)\end{array}$ & $(6.6,9.4)$ & $(6.9,8.2)$ & $(10.7,13.8)$ & $\begin{array}{l}(12.7 \\
14.8)\end{array}$ \\
\hline \multirow[t]{2}{*}{4} & \multirow[t]{2}{*}{301} & \multirow{2}{*}{$\begin{array}{l}67 \\
(22.3 \%)\end{array}$} & 0.90 & 0.88 & \multirow{2}{*}{$\begin{array}{l}161 \\
(53.5 \%)\end{array}$} & 3.04 & 2.21 & 7.8 & 6.6 & 11.8 & 12.8 \\
\hline & & & $\begin{array}{l}(0.49 \\
1.65) ; p= \\
0.74)\end{array}$ & $\begin{array}{l}(0.47 \\
1.63 ; p= \\
0.68)\end{array}$ & & $\begin{array}{l}(2.06,4.48 \\
p<0.001)\end{array}$ & $\begin{array}{l}(1.48 \\
3.30 ; p< \\
0.001)\end{array}$ & $(6.6,9.4)$ & $(5.9,7.2)$ & $(9.6,14.6)$ & $\begin{array}{l}(11.7 \\
13.8)\end{array}$ \\
\hline \multirow[t]{2}{*}{5} & \multirow[t]{2}{*}{180} & \multirow{2}{*}{$\begin{array}{l}49 \\
(27.2 \%)\end{array}$} & 1.16 & 0.99 & \multirow{2}{*}{$\begin{array}{l}109 \\
(60.6 \%)\end{array}$} & 4.04 & 2.70 & 7.5 & 5.6 & 10.6 & 11.8 \\
\hline & & & $\begin{array}{l}(0.61,2.19 ; \\
p=0.65)\end{array}$ & $\begin{array}{l}(0.51 \\
1.90 ; p= \\
0.97)\end{array}$ & & $\begin{array}{l}(2.62,6.24 \\
p<0.001)\end{array}$ & $\begin{array}{l}(1.71 \\
4.25 ; p< \\
0.001)\end{array}$ & $(5.6,10.0)$ & $(4.8,6.4)$ & $(8.6,13.2)$ & $\begin{array}{l}(10.7 \\
13.0)\end{array}$ \\
\hline 6 & 124 & 33 & 1.28 & 1.15 & 89 & 4.62 & 3.16 & 8.2 & 4.6 & 11.3 & 10.8 \\
\hline & & & $\begin{array}{l}(0.64,2.55 \\
\mathrm{p}=0.48)\end{array}$ & $\begin{array}{l}(0.57 \\
2.33 ; p= \\
0.70)\end{array}$ & & $\begin{array}{l}(2.85,7.51 ; \\
p<0.001)\end{array}$ & $\begin{array}{l}(1.91 \\
5.23 ; p< \\
0.001)\end{array}$ & $(6.2,11.0)$ & $(3.6,5.7)$ & $(7.9,16.0)$ & $\begin{array}{l}(9.5 \\
12.2)\end{array}$ \\
\hline 7 & 70 & $\begin{array}{l}17 \\
(24.3 \%)\end{array}$ & 0.90 & 0.80 & $\begin{array}{l}43 \\
(61.4 \%)\end{array}$ & 3.91 & 2.61 & $7.9^{* *}$ & $3.6^{* *}$ & $7.3^{\star \star}$ & $9.9^{\star \star}$ \\
\hline & & & $\begin{array}{l}(0.41,1.97 \\
\mathrm{p}=0.80)\end{array}$ & $\begin{array}{l}(0.36 \\
1.78 ; p= \\
0.59)\end{array}$ & & $\begin{array}{l}(2.20,6.94 \\
p<0.001)\end{array}$ & $\begin{array}{l}(1.44 \\
4.73 ; p= \\
0.002)\end{array}$ & $(5.2,12.0)$ & $(2.3,5.0)$ & $(4.6,11.6)$ & $\begin{array}{l}(8.2, \\
11.5)\end{array}$ \\
\hline 8 & 14 & $5(35.7 \%)$ & 1.26 & 1.05 & 12 & 14.73 & 14.20 & & & & \\
\hline & & & $\begin{array}{l}(0.36,4.35 \\
p=0.72)\end{array}$ & $\begin{array}{l}(0.30 \\
3.74 ; p= \\
0.94)\end{array}$ & & $\begin{array}{l}(3.19,67.9 \\
p=0.001)\end{array}$ & $\begin{array}{l}(2.98 \\
67.6 ; p= \\
0.001)\end{array}$ & & & & \\
\hline
\end{tabular}

ICU - intensive care unit, OR - odds ratio, 95\%-Cl - 95\% confidence interval

${ }^{*}$ Dichotomized unadjusted analysis for frail vs. non-frail patients: ICU mortality: $26.8 \%$ vs. $17.9 \%$; $p=0.044$; Hospital mortality: $65.2 \%$ vs. $41.8 \%$; $p<0.001$

${ }^{* *}$ Note: Due to small sample numbers, CFS $7 \& 8$ were combined for duration of mechanical ventilation

^ Dichotomous comparison: non-frail vs. frail adjusted geometric mean for mechanical ventilation in survivors = 7.7 (7.0, 8.3) vs. 4.6 (3.5, 5.7); $\mathrm{p}<0.001$

${ }^{\wedge \wedge}$ Dichotomous comparison: non-frail vs. frail adjusted geometric mean for mechanical ventilation in non-survivors $=13.9(12.8,15.0)$ vs. $10.8(9.5,12.3)$; $p<$ 0.001

\section{Figures}


Figure 1: Hospital mortality according to Clinical Frailty Scale (CFS) score for all patients adjusted for age and sex. Panel (a) is the raw (unadjusted) data by CFS. Panel (b) is the data adjusted for age and sex. Panel (c) is as for patients receiving invasive mechanical ventilation.
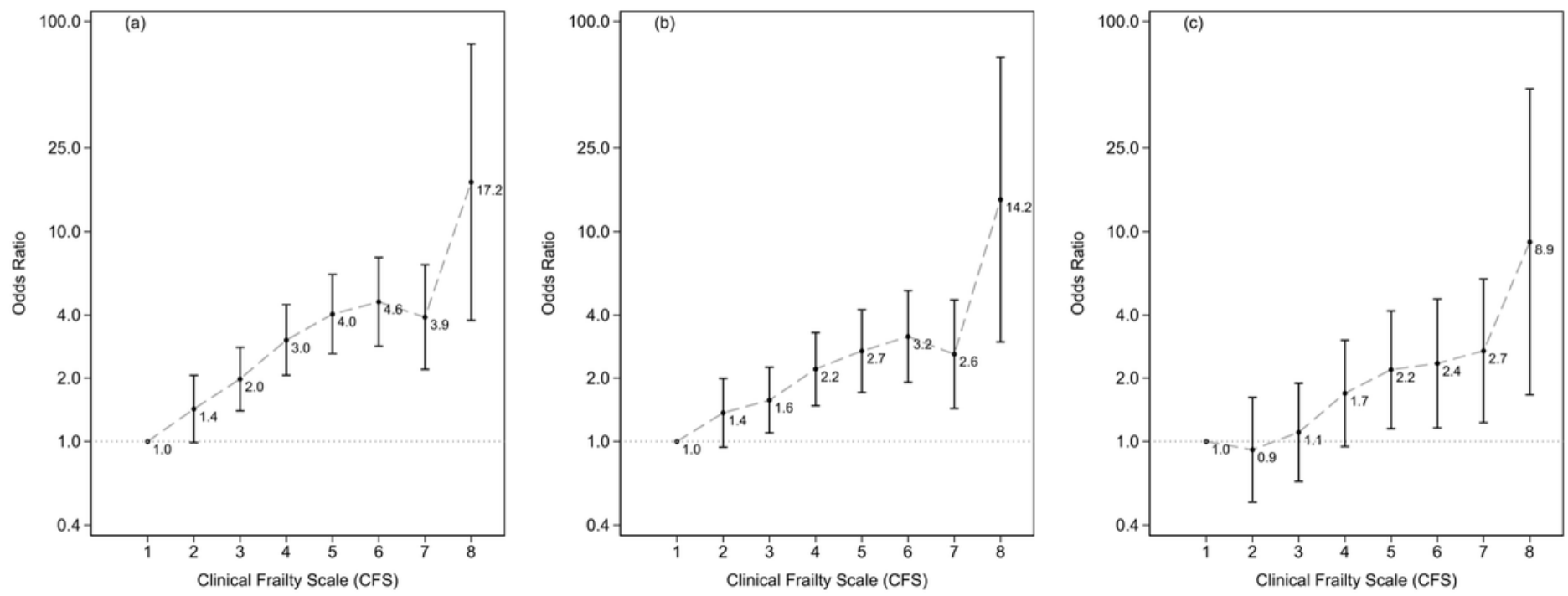

Figure 1

Hospital mortality according to Clinical Frailty Scale (CFS) score for all patients adjusted for age and sex. Panel (a) is the raw (unadjusted) data by CFS. Panel (b) is the data adjusted for age and sex. Panel (c) is as for (b) with ventilation included.

Figure 2: Graphical representation of cumulative incidence of death for frailty.

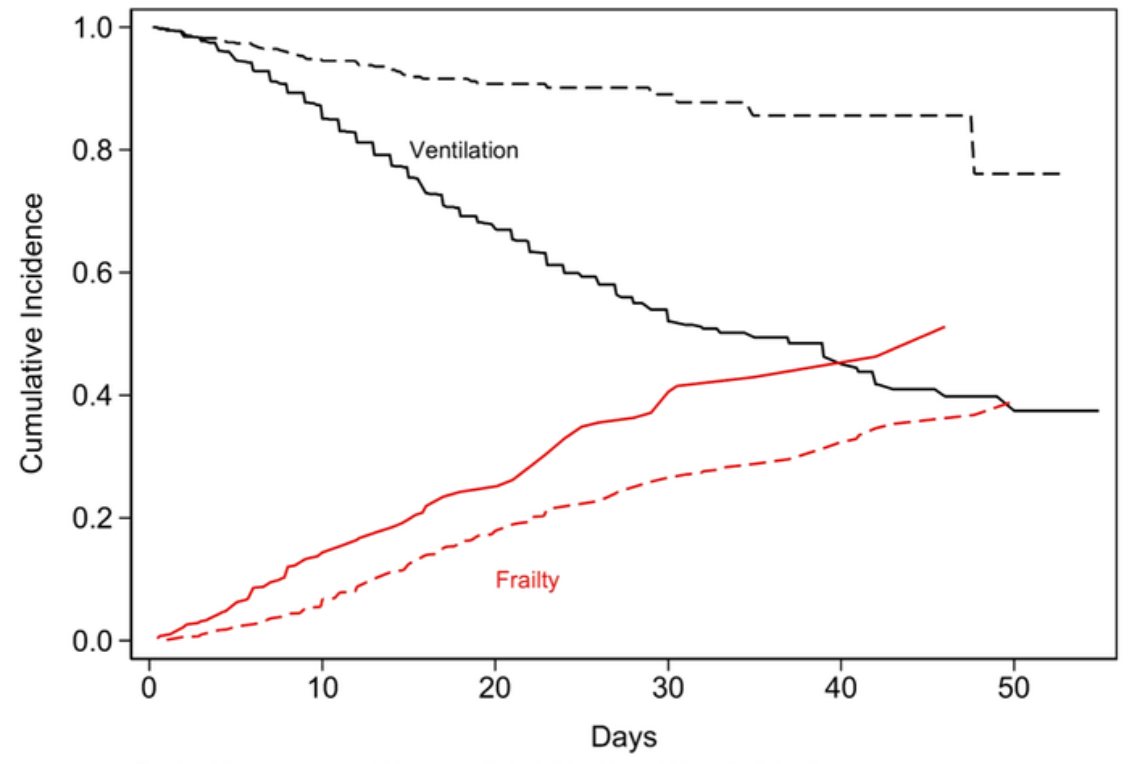

Dashed lines represent Non-ventilated (black) and Non-frail (red) 
Graphical representation of cumulative incidence of death for frailty.

Figure 3: Total ICU bed-days stratified by Clinical Frailty Scale (CFS) comparing survivors and non-survivors.

\section{Occupied bed-days by CFS}

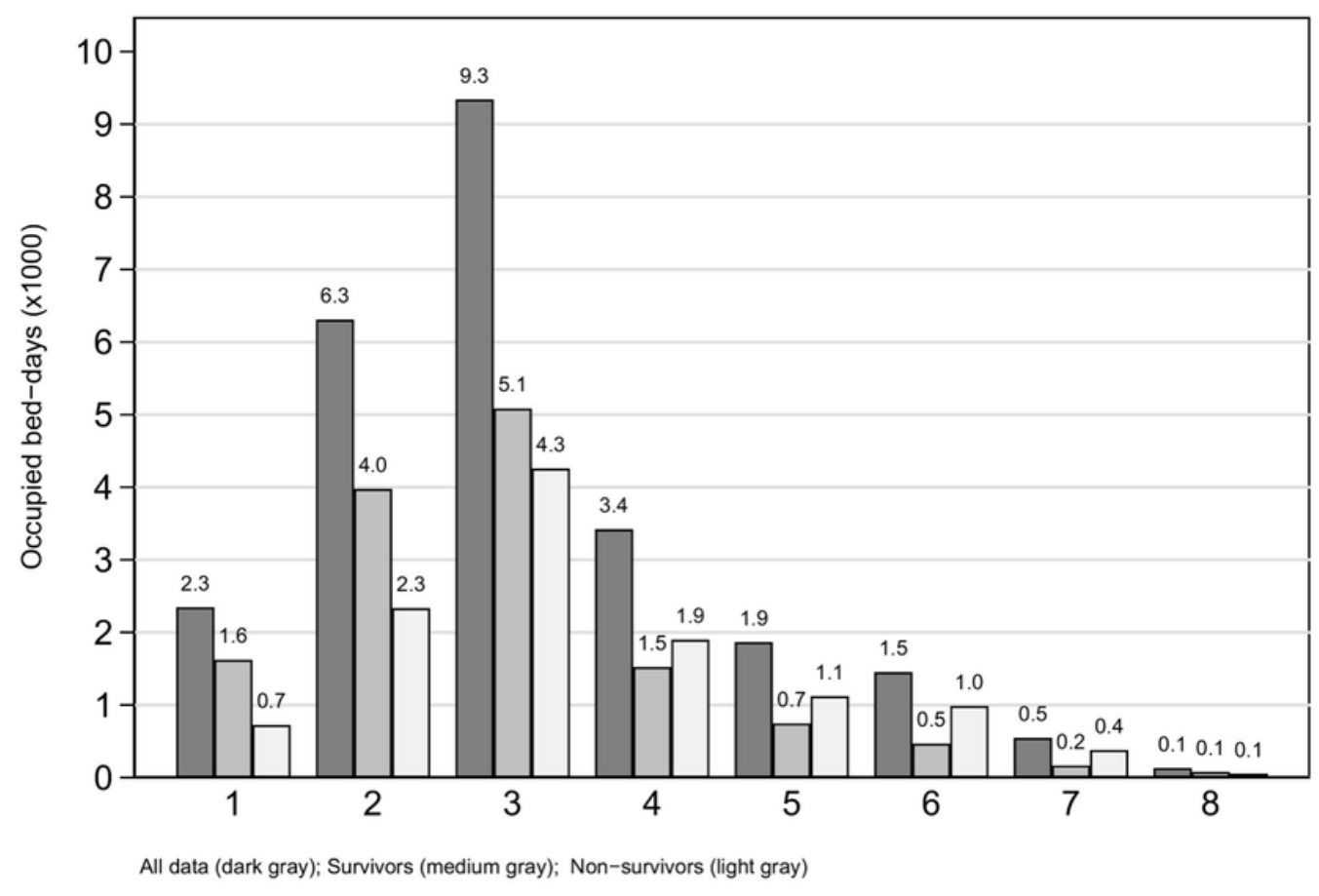

Figure 3

Total ICU bed-days stratified by Clinical Frailty Scale (CFS) comparing survivors and non-survivors.

\section{Supplementary Files}

This is a list of supplementary files associated with this preprint. Click to download.

- PRISMAIPDchecklist.pdf

- SupplementaryMaterials.pdf 